\title{
Aerobic physical exercise and arterial de-stiffening: a recipe for vascular rejuvenation?
}

\author{
Giacomo Pucci, Francesca Battista and Giuseppe Schillaci \\ Hypertension Research (2012) 35, 964-966; doi:10.1038/hr.2012.107; published online 12 July 2012
}

\begin{abstract}
Substantial evidence indicates that physical $\checkmark$ activity, exercise training and overall cardiorespiratory fitness have a favorable impact on cardiovascular health. ${ }^{1}$ Over the short term, physical activity exerts multiple beneficial effects on all major modifiable cardiovascular risk factors, including blood pressure (BP), obesity, glucose and lipid levels, and on a variety of other conditions, such as anxiety, depression, cancer and pain control. ${ }^{1}$ These short-term benefits translate into significant long-term reductions in the risk of cardiovascular events and mortality., ${ }^{2,3}$

Chronic dynamic aerobic exercise is an established measure for reducing office and 24-h BP, although its net effects on BP are rather modest. Some postulated mechanisms through which exercise may improve cardiovascular hemodynamics include heart-rate lowering, increased cardiac output and stroke volume and a reduced total peripheral resistance, the latter mediated by a number of different mechanisms including decreased norepinephrine and renin production. ${ }^{4}$
\end{abstract}

An additional potential mechanism through which aerobic physical exercise may reduce $\mathrm{BP}$ is by reducing aortic stiffness. Increased vascular stiffness is increasingly believed to have a key role in cardiovascular disease through amplified pulse pressure, reduced pressure buffering and increased propagation of ventricular tension, ${ }^{5}$ and is a primary marker of cardiovascular disease risk. ${ }^{6}$ A number of observational studies ${ }^{7-10}$ have generally shown an inverse correlation between levels of physical exercise and carotid-femoral pulse wave velocity

G Pucci, F Battista and G Schillaci are at the Unit of Internal Medicine, Department of Clinical and Experimental Medicine, University of Perugia, S. Maria Hospital, Terni, Italy.

E-mail: skill@unipg.it
(cfPWV) at all ages and for every amount of exercise workload, even after accounting for the effects of several confounders. In a sample of 109 unfit elderly individuals, Gando et al. ${ }^{9}$ found that cfPWV had an inverse association with the time spent in light physical activities, such as house work and other unstructured physical exercise. These results suggest that longer time spent in light physical activity is associated with an attenuation of arterial stiffening in unfit people.

Cross-sectional studies, however, demonstrate associations but may not establish cause-and-effect relationships. The prove of a causal link between exercise and arterial de-stiffening relies upon prospective studies. A few intervention studies carried out in small groups of subjects have suggested that aerobic exercise may reduce aortic stiffness ${ }^{11-15}$ (Table 1). In the present issue of Hypertension Research, Fantin et al. ${ }^{16}$ further explore the above area in a prospectively designed study. They evaluated 21 normotensive or hypertensive community-dwelling women aged between 60 and 80 years with no overt cardiovascular disease, who were involved in a light-to-moderate aerobic exercise program for 6 months. Aerobic exercise consisted in a supervised brisk walking at the $75 \%$ of maximum heart rate twice a week. At baseline and follow-up, the study subjects underwent a comprehensive clinical evaluation including measurement of aortic (carotid-femoral) and upper-limb (carotidradial) vascular stiffness with the Complior device, with the time delay between carotid and femoral pulse waves calculated by the foot-to-foot method. A fairly good rate of attendance at walking session was observed throughout the study, with $20 \%$ of drop-out rate in the first trimester and a further $15 \%$ in the second trimester.
In the whole group, cfPWV was reduced by about $6 \%$ at 6 months $\left(12.1 v s .11 .3 \mathrm{~m} \mathrm{~s}^{-1}\right.$, $P=0.02)$, whereas carotid-radial PWV was not influenced by exercise $\left(9.2 v s .9 .1 \mathrm{~m} \mathrm{~s}^{-1}\right.$, $P=0.75)$. Exercise was also associated with reduction in waist circumference, abdominal sagittal diameter and serum triglycerides. No significant changes in $\mathrm{BP}$ and $\mathrm{HR}$ were observed and changes in CfPWV were independent of changes in $\mathrm{BP}$, heart rate and adiposity measures observed between baseline and follow-up. As expected, hypertensive subjects ( $45 \%$ of the total sample) had a higher baseline cfPWV than normotensives (13.2 vs. 11.7, $P=0.05$ ). They also showed a more pronounced reduction in cfPWV after training (12.8 vs. 11.9, $P=0.02)$ than normotensives (11.7 vs. 11.3, $P=0.15$ ), although the hypothesis of a greater effect of exercise on cfPWV in hypertensive than in normotensive subjects was not tested formally, and the possibility of a 'regression toward the mean' effect was not considered.

The present study adds to a number of investigations, which have consistently shown a reduction in cfPWV over the short term, following different lifestyle interventions, including not only physical exercise ${ }^{11-16}$ but also weight loss, smoking cessation and salt intake restriction $^{17-25}$ (Table 1).

Which potential mechanisms may explain the observed short-time reduction in cfPWV after physical exercise? Arterial stiffness is a measure of the nonlinear relationship between wall stress and deformability, and reflects the increase of arterial pressure at increasing volume. cfPWV is a widely used surrogate measure of arterial stiffness, which expresses the speed of pressure wave along the carotid-to-femoral path and is inversely related to elastic modulus and distensibility. cfPWV increases exponentially with age and 
Table 1 Change in carotid-femoral pulse wave velocity (cfPWV) after non-drug interventions in prospective studies

\begin{tabular}{|c|c|c|c|c|c|}
\hline Population & $\mathrm{n}$ & Intervention & Duration & $\begin{array}{c}\text { cfPWV change, } \% \\
\text { (baseline vs. post-intervention, } m s^{-1} \text { ) }\end{array}$ & Reference \\
\hline \multicolumn{6}{|l|}{ Aerobic exercise } \\
\hline Young sedentary & 10 & Aerobic exercise ( $70 \%$ maximal HR) & 8 weeks & $-5 \%(5.8 \text { vs. } 5.5)^{*}$ & Kakiyama et al. ${ }^{11}$ \\
\hline Pre-HTN or HTN & 15 & Aerobic exercise (65\% maximal HR) & 4 weeks & $-8 \%(12.1 \text { vs. } 11.1)^{*}$ & Collier et al. ${ }^{12}$ \\
\hline ESRD under hemodialysis & 19 & Aerobic exercise & 6 months & $-11 \%(10.2 \text { vs. } 9.0)^{* *}$ & Toussaint et al. ${ }^{13}$ \\
\hline HTN & 16 & Interval exercise (50-80\% HR reserve) & 16 weeks & $-6 \%(9.4 \text { vs. } 8.9)^{* *}$ & Guimarães et al. ${ }^{14}$ \\
\hline Obese with IGT & 12 & Aerobic exercise ( $65 \%$ maximal HR) & 12 weeks & $-8 \%(9.1 \text { vs. } 8.4)^{*}$ & McNeilly et al. ${ }^{15}$ \\
\hline Elderly women & 21 & Aerobic exercise ( $75 \%$ maximal HR) & 6 months & $-6 \%(12.1 \text { vs. } 11.3)^{*}$ & Fantin et al. ${ }^{16}$ \\
\hline \multicolumn{6}{|l|}{ Weight loss } \\
\hline Obese & 28 & Diet $(n=16)$, bariatric surgery $(n=12)$ & 1 year & $-14 \%(5.8 \text { vs. } 5.0)^{*}$ & Rider et al. ${ }^{17}$ \\
\hline Overweight or obese & 25 & Diet & 12 weeks & $-16 \%(11.6 \text { vs. } 9.7)^{*}$ & Dengo et al. ${ }^{18}$ \\
\hline Obese & 12 & Diet & 12 weeks & $-6 \%(9.8 \text { vs. } 9.2)^{*}$ & Miyaki et al. ${ }^{19}$ \\
\hline Type 2 diabetes & 38 & Diet & 1 year & $-7 \%(7.4 \text { vs. } 6.9)^{*}$ & Barinas-Mitchell et al. ${ }^{20}$ \\
\hline Overweight with HTN & 55 & Diet & 3 months & $-16 \%(7.5 \text { vs. } 6.3)^{*}$ & Clifton et al. ${ }^{21}$ \\
\hline \multicolumn{6}{|l|}{ Smoking cessation } \\
\hline Smokers & 37 & Counseling + varenicline & 12 weeks & $-12 \%(17.7 \text { vs. } 15.6)^{\mathrm{a} * *}$ & Takami and Saito 22 \\
\hline \multicolumn{6}{|l|}{ Salt intake reduction } \\
\hline Pre-HTN or HTN & 35 & High vs. low sodium intake & 4 weeks & $-6 \%(7.9 \text { vs. } 7.4)^{* *}$ & Todd et al. ${ }^{23}$ \\
\hline Untreated mild HTN & 169 & Sodium vs. placebo intake & 6 weeks & $-3 \%(11.5 \text { vs. } 11.1)^{* *}$ & He et al. ${ }^{24}$ \\
\hline $\begin{array}{l}\text { Pre-HTN or HTN post-menopausal } \\
\text { women }\end{array}$ & 35 & Dietary sodium restriction & 3 months & $-13 \%(8.7 \text { vs. } 7.6)^{*}$ & Seals et al. ${ }^{25}$ \\
\hline
\end{tabular}

Abbreviations: ESRD, end-stage renal disease; HR, heart rate; HTN, hypertension; IGT, impaired glucose tolerance.

aBrachial-ankle PWV.

${ }^{*} P<0.05$.

$* * P<0.01$.

is a well-known measure of aortic ageing. ${ }^{26}$ Numerous studies have shown that increased cfPVW is the consequence of structural alterations of the aortic wall, such as elastin fatigue, fracture and fragmentation, and increased deposition and cross-linking of matrix collagen fibers. Thus, short-term changes in cfPWV may reflect structural de-stiffening, with breaking of connective tissue cross-linking.

On the other hand, changes in cfPWV may also reflect favorable changes in the functional determinants of stiffness. Although cfPWV is a relatively straightforward and simple measure of aortic stiffness, it may not fully account for the complexity of the physical mechanisms and interactions involved in the determination of aortic compliance. A number of observations challenge the intuitive concept of stiffness as a static phenomenon, in favor of a more comprehensive dynamic view. Several experimental and epidemiological studies showed that arterial stiffness is critically dependent on distending pressure (expressed as mean arterial pressure), ${ }^{27,28}$ as well as on other determinants subjected to physiological variability, such as heart rate, myocardial geometry and strength of contraction, arterial smooth muscle tone, nitric oxide bioavailability and vascular diameter. ${ }^{29,30}$
More recently, it has been observed that stiffness of a given segment continuously changes over a single cardiac circle from diastole to systole because of its dependence on instantaneous distending $\mathrm{BP}^{31}$ Aortic stiffness may act both as a determinant and a consequence of the efficiency of the interaction between the heart and arterial system (named ventricular-vascular coupling), in which the left ventricle and peripheral arteries are functionally coupled with large arteries. ${ }^{32}$ Indeed, ventricular-vascular interactions have an essential role in the responses of the cardiovascular system to stress demands, ${ }^{33}$ and the arterial system undergoes structural and functional adaptations to increased stroke volume in fit individuals, including, for instance, increased conduit artery size and increase in total cross-sectional area of resistance arteries. $^{34}$ Thus, short-term changes in arterial stiffness may reflect the adaptations of the whole cardiovascular system to the hemodynamic changes induced by physical exercise, which are mirrored only in part by changes in BP and heart rate.

The study by Fantin et al. ${ }^{16}$ has a number of important limitations, including the lack of data on cardiac and peripheral vascular function and arterial wave reflection. Moreover, the absence of a control group does not allow the authors to draw conclusions about the net effects of aerobic training on vascular stiffness. Despite these shortcomings, the results of the study, in line with previous observations, further reinforce the view that even light physical activity should be recommended at all ages because of its unequivocal favorable cardiovascular effects. However, only a comprehensive investigation of the relationship between exercise-induced changes in arterial stiffness and changes in cardiac and vascular function will allow researchers to clarify the meaning of short-term changes in cfPWV in this setting.

\section{CONFLICT OF INTEREST}

The author declares no conflict of interest

1 Warburton DE, Nicol CW, Bredin SS. Health benefits of physical activity: the evidence. CMAJ 2006; 174: 801-809.

2 Blair SN, Kohl 3rd HW, Paffenbarger Jr RS, Clark DG, Cooper KH, Gibbons LW. Physical fitness and all-cause mortality. A prospective study of healthy men and women. JAMA 1989; 262: 2395-2401.

3 Archer E, Blair SN. Physical activity and the prevention of cardiovascular disease: from evolution to epidemiology. Prog Cardiovasc Dis 2011; 53: 387-396.

4 Cornelissen VA, Fagard RH. Effects of endurance training on blood pressure, blood pressure-regulating 
mechanisms, and cardiovascular risk factors. Hyperten sion 2005; 46: 667-675.

5 Nichols WW, O'Rourke MF, Vlachopoulos C. Mc Donald's Blood Flow in Arteries: Theoretical, Experimental and Clinical Principles (6th edn). Hodder Arnold, London, UK, 2011.

6 Mitchell GF, Hwang SJ, Vasan RS, Larson MG, Pencina MJ, Hamburg NM, Vita JA, Levy D, Benjamin EJ. Arterial stiffness and cardiovascular events: the Framingham Heart Study. Circulation 2010; 121: 505-511.

7 Vaitkevicius PV, Fleg JL, Engel JH, O'Connor FC, Wright JG, Lakatta LE, Yin FC, Lakatta EG. Effects of age and aerobic capacity on arterial stiffness in healthy adults. Circulation 1993; 88: 1456-1462.

8 Tanaka H, DeSouza CA, Seals DR. Absence of agerelated increase in central arterial stiffness in physically active women. Arterioscler Thromb Vasc Biol 1998; 18: 127-132.

9 Gando Y, Yamamoto K, Murakami H, Ohmori Y, Kawakami R, Sanada K, Higuchi M, Tabata I, Miyachi M. Longer time spent in light physical activity is associated with reduced arterial stiffness in older adults. Hypertension 2010; 56: 540-556.

10 Edwards NM, Daniels SR, Claytor RP, Khoury PR, Dolan LM, Kimball TR, Urbina EM. Physical activity is independently associated with multiple measures of arterial stiffness in adolescents and young adults. Metabolism 2011; 61: 869-872.

11 Kakiyama T, Sugawara J, Murakami H, Maeda S, Kuno S, Matsuda M. Effects of short-term endurance training on aortic distensibility in young males. Med Sci Sports Exerc 2005; 37: 267-271.

12 Collier SR, Kanaley JA, Carhart Jr R, Frechette V, Tobin MM, Hall AK, Luckenbaugh AN, Fernhall B. Effect of 4 weeks of aerobic or resistance exercise training on arterial stiffness, blood flow and blood pressure in preand stage-1 hypertensives. J Hum Hypertens 2008; 22: 678-686.

13 Toussaint ND, Polkinghorne KR, Kerr PG. Impact of intradialytic exercise on arterial compliance and B-type natriuretic peptide levels in hemodialysis patients. Hemodial Int 2008; 12: 254-263.

14 Guimarães GV, Ciolac EG, Carvalho VO, D’Avila VM, Bortolotto LA, Bocchi EA. Effects of continuous vs interval exercise training on blood pressure and arterial stiffness in treated hypertension. Hypertens Res 2010; 33: 627-632.
15 McNeilly AM, McClean C, Murphy M, McEneny J, Trinick T, Burke G, Duly E, McLaughlin J, Davison G. Exercise training and impaired glucose tolerance in obese humans. J Sports Sci 2012; 30: 725-732

16 Fantin F, Rossi A, Morgante S, Soave D, Bissoli L, Cazzadori M, Vivian ME, Valsecchi M, Zamboni M. Supervised walking groups to increase physical activity in elderly women with and without hypertension: effect on pulse wave velocity. Hypertens Res 2012 35: 988-993.

17 Rider OJ, Tayal U, Francis JM, Ali MK, Robinson MR, Byrne JP, Clarke K, Neubauer S. The effect of obesity and weight loss on aortic pulse wave velocity as assessed by magnetic resonance imaging. Obesity (Silver Spring) 2010; 18: 2311-2316.

18 Dengo AL, Dennis EA, Orr JS, Marinik EL, Ehrlich E, Davy BM, Davy KP. Arterial destiffening with weight loss in overweight and obese middleaged and older adults. Hypertension 2010; 55 855-861.

19 Miyaki A, Maeda S, Yoshizawa M, Misono M, Saito Y, Sasai H, Endo T, Nakata Y, Tanaka K, Ajisaka R. Effect of weight reduction with dietary intervention on arterial distensibility and endothelial function in obese men. Angiology 2009; 60: 351-357.

20 Barinas-Mitchell E, Kuller LH, Sutton-Tyrrell K, Hegazi R, Harper P, Mancino J, Kelley DE. Effect of weight loss and nutritional intervention on arterial stiffness in type 2 diabetes. Diabetes Care 2006; 29: 2218-2222.

21 Clifton PM, Keogh JB, Foster PR, Noakes M. Effect of weight loss on inflammatory and endothelial markers and FMD using two low-fat diets. Int J Obes 2005; 29 1445-1451.

22 Takami T, Saito Y. Effects of smoking cessation on central blood pressure and arterial stiffness. Vasc Health Risk Manag 2011; 7: 633-638.

23 Todd AS, Macginley RJ, Schollum JB, Johnson RJ, Williams SM, Sutherland WH, Mann JI, Walker RJ. Dietary salt loading impairs arterial vascular reactivity. Am J Clin Nutr 2010; 91: 557-564.

24 He FJ, Marciniak M, Carney C, Markandu ND, Anand V, Fraser WD, Dalton RN, Kaski JC, MacGregor GA Effects of potassium chloride and potassium bicarbonate on endothelial function, cardiovascular risk factors, and bone turnover in mild hypertensives. Hypertension 2010; 55: 681-688.
25 Seals DR, Tanaka H, Clevenger CM, Monahan KD Reiling MJ, Hiatt WR, Davy KP, DeSouza CA. Blood pressure reductions with exercise and sodium restriction in postmenopausal women with elevated systolic pressure: role of arterial stiffness. J Am Coll Cardiol 2001; 38: 506-513.

26 Kotsis V, Stabouli S, Karafillis I, Nilsson P. Early vascular aging and the role of central blood pressure. J Hypertens 2011; 29: 1847-1853.

27 McEniery CM, Yasmin Y, Hall IR, Qasem A, Wilkinson IB, Cockcroft JRACCT Investigators. Normal vascular aging: differential effects on wave reflection and aortic pulse wave velocity: the Anglo-Cardiff Collaborative Trial (ACCT). J Am Coll Cardiol 2005, 46: 1753-1760.

28 Schillaci G, Pucci G, Pirro M, Settimi L, Hijazi R, Franklin SS, Mannarino E. Combined effects of office and 24-h blood pressure on aortic stiffness in human hypertension. J Hypertens 2011; 29: 869-875.

29 Schillaci G, Mannarino MR, Pucci G, Pirro M, Helou J, Savarese G, Vaudo G, Mannarino E. Age-specific relationship of aortic pulse wave velocity with left ventricular geometry and function in hypertension. Hypertension 2007; 49: 317-321.

30 Vlachopoulos C, loakeimidis N, Terentes-Printzios D, Aznaouridis K, Baou K, Bratsas A, Lazaros G, Stefanadis $\mathrm{C}$. Amino-terminal pro-C-type natriuretic peptide is associated with arterial stiffness, endothelial function and early atherosclerosis. Atherosclerosis 2010; 211: 649-655.

31 Hermeling E, Vermeersch SJ, Rietzschel ER, de Buyzere ML, Gillebert TC, van de Laar RJ, Ferreira I, Hoeks AP, van Bortel LM, Reneman RS, Segers P, Reesink KD. The change in arterial stiffness over the cardiac cycle rather than diastolic stiffness is independently associated with left ventricular mass index in healthy middle-aged individuals. J Hypertens 2012; 30: 396-402.

32 Kass DA. Ventricular arterial stiffening: integrating the pathophysiology. Hypertension 2005; 46: 185-193.

33 Chantler PD, Lakatta EG, Najjar SS. Arterial-ventricular coupling: mechanistic insights into cardiovascular performance at rest and during exercise. J Appl Physiol 2008; 105: 1342-1351.

34 Green DJ, Spence A, Rowley N, Thijssen DH, Naylor LH. Vascular adaptation in athletes: is there an 'athlete's artery'? Exp Physiol 2012; 97: 295-304. 